\title{
FILOZOFIJA, METODOLOGIJA IN VIZIJA RAZVOJA PODEŽELJA
}

\author{
Vilibald Premzl* Mirko Pšunder**
}

Izvleček

UDK $910.1(1-22)$

$V$ članku so prikazani osnovni elementi planiranja s posebnim ozirom na podeželski prostor. Izpostavljena je potreba po izvajanju politike razvoja podeželskega prostora, ki mu je tudi v Sloveniji na vseh ravneh posvečene premalo pozornosti.

Ključne besede: Ekologija, krajina, naravna dediščina, nega prostora, odprtì prostor, gospodarsko planiranje, varstvo narave, Slovenija

Abstract

UDC $910.1(1-22)$

PHYLOSOPHY, METHODOLOGY AND THE VISION OF COUNTRYSIDE DEVELOPMENT

The article presents planning elements with special references to countryside areas. It is emphasired the need for emplementation of development policy in Slovenia because not enough intentions are devored to these problems.

Key words: Ecology, landscape, natur heritage, preservation areas, open space, economic planning, conservation of nature, Slovenia

\section{UVOD}

Planiranje je dejavnost, s katero poskušamo urejati življenje v sedanjem in prihodnjem času na določenem območju. Urejanje prostora in njegovih sestavin se po eni od definicij deli na tri ravni:

- Fizično planiranje, s katerim zagotavljamo na prvi ravni boljšo rabo tal za naselitev, gospodarske dejavnosti, prometnice, rekreacijo, usmerjen in organiziran urbani razvoj, turizem, itd. Tako planiranje je statično in teritorialno opredeljeno.

- Regionalno planiranje na drugi ravni ureja prostor z regionalnim/prostorskim/planiranjem. Cilj planiranja je zviševati življenjsko raven v celotnem prostoru in zmanjšati regionalne razlike $\mathrm{v}$ stopnji razvoja.To planiranje je dinamično, je prostorsko funkcionalno in ekonomsko smiselno. -Planiranje organizacije prostora je tretja raven; je politika s katero uvajamo organizacijo prostora in človeških bivališč, prostorski red, kar naj bi omogočilo ljudem najboljše življenske razmere.

* Dr,,izr. prof., Tehniška fakulteta, Univerza v Mariboru, 62000 Maribor, Smetanova 17, SLO

** Dr., prof., Tehniška fakulteta, Univerza v Mariboru, 62000 Maribor, Smetanova 17, SLO 


\section{PODEŽELSKI PROSTOR KOT PREDMET PLANIRANJA}

Od sprejetja predstavljenih definicij do danes je prišlo v pojmovanju prostorskega planiranja do novih spoznanj in novih pogledov. Najčešč se $\mathrm{v}$ povezavi s prostorskim planiranjem pojavlja pojem ekologija, odnosno planiranje prostorske ekologije in varovalno planiranje prostora. Zelo realna slika odnosov med človekom in prostorom je podana v priročniku za planiranje Buchwalda in Engelhardta, kjer je prostor človekovih aktivnosti poimenovan s pojmom prostorsko okolje. (Buchwald, 1980)

Kakor koli že, rabo prostora v klasičnem pomenu besede dejansko planiramo. Predvsem je urbani prostor predmet planiranja vrste strokovnjakov, ki izdelujejo, več ali manj vsklajeno, vrsto sektorskih planov, ki se izvajajo po logiki izvajanja planov. Pri tem so jasno opredeljeni cilji, roki izvedbe, tehnična rešitev in stroški za izvedbo posameznega plana ali celotnega urbanističnega projekta. Tudi vsebina in metodologija planiranja sta na osnovi zakonskih in podzakonskih predpisov jasno opredeljena. Vse bi se naj končalo v realizaciji določenega projekta.

Bistveno manj pa so bila prizadevanja zakonodajalcev in strokovnjakov, planerjev, usmerjena $\mathrm{v}$ podeželski prostor.

Podeželski prostor obravnavamo predvsem v naslednjih funkcijah:

- bivalni in delovni prostor podeželskega prebivalstva,

- lokacije za pridelavo hrane in surovin/ kmetijstvo in gozdarstvo/,

- lokacije podeželske obrti ni decentralizirane industrije,

- rezervat za širitev naselij, industrije za trase prometnic in za vse vrste infrastrukturnih naprav in vodov,

- prostor za rekreacijo in sprostitev,

- ekološki izravnalni prostor $\mathrm{z}$ varovalnim učinkom za naravne temeljne dobrine in za varovalna območja vseh vrst naravnih dobrin.

Deagrarizacija in velike družbene spremembe $v$ tem stoletju so tudi pri nas povzročile nekaj bistvenih sprememb v podeželskem prostoru:

- zmanjšanje podeželskega prebivalstva,

- povečanje storitvenih in oskrbnih dejavnosti, povečanje ali odpiranje proizvodnih obratov, razvoj turističnega gospodarstva in gostinstva,

- socialne spremembe $\mathbf{v}$ sestavi prebivalstva in spremembe tradicionalnih vrednot podeželskega prebivalstva,

- mobilnost podeželskga prebivalstva in dnevne migracije,

- razvrednotenje tradicionalne krajinske in naselbinske identitete. 
Filozofija, metodologija in vizija...

\section{RAZVOJNI POTENCIAL PODEŽELSKEGA PROSTORA}

In kakšen razvojni potencial premore, ob splošno znanem potencialu mestnega prostora, podeželski prostor?

Računamo z naslednjimi potenciali:

- prebivalstvom,

- naselji in naselbinsko strukturo,

- kmetijskimi zemljišči,

- gozdovi,

- vodami,

- možnostmi za rekreacijo in turizem /predvsem v visokogorskem in hribovitem svetu/,

- ekološko nerazvrednotenim prostorom.

Pregled teh potencialov kaže na bistveno drugačne potenciale, kot smo jih vajeni na področju prostorkega ali urbanističnega načrtovanja. Postavlja se vprašanje: na kakšen način lahko izvedemo $\mathrm{v}$ uvodu predstavljene tri ravni planiranja $\mathrm{v}$ podeželskem prostoru?

V preteklem tridesetletju so se pri planiranju in urejanju podeželja uveljavili naslednji načini: - ruralno planiranje ali planiranje rabe zemljišč za pretežno kmetijsko proizvodnjo,

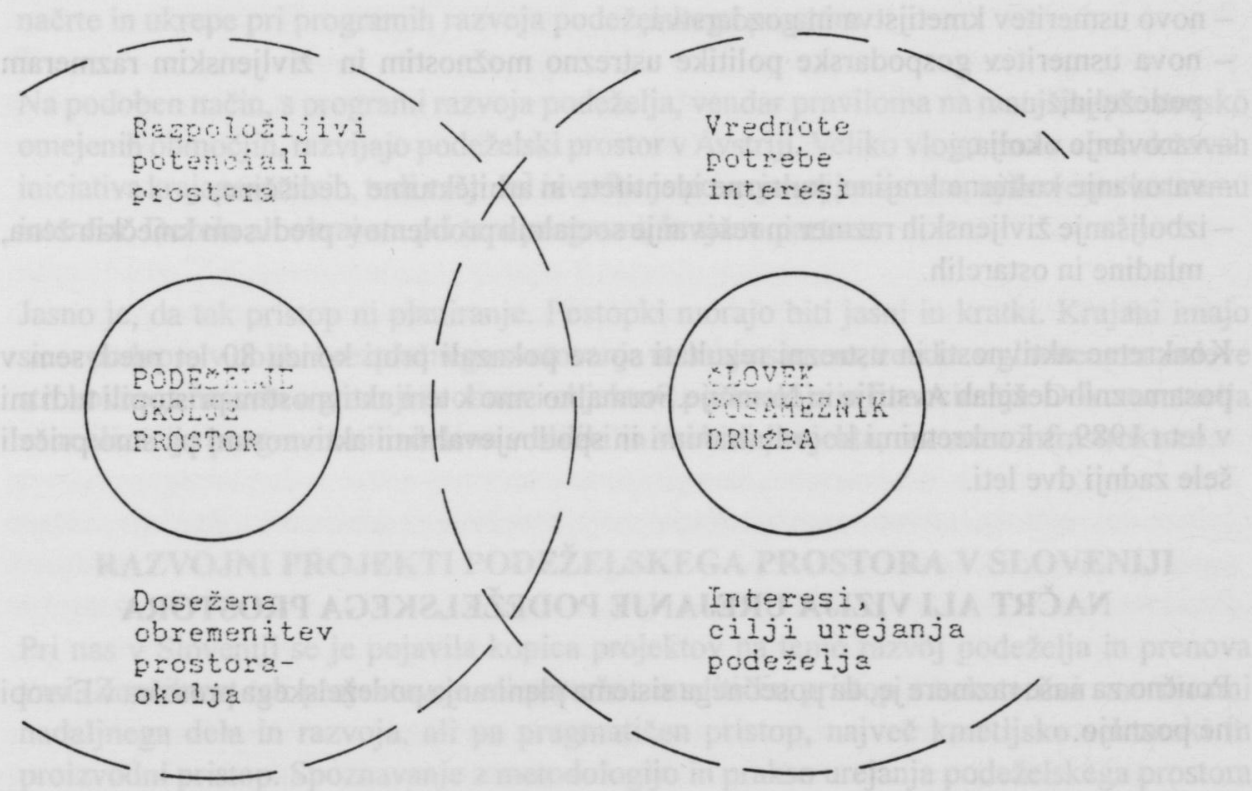

Slika 1: Soodvisnost razvoja podeželja in ciljev družbe

Zusammenhang der Landesentwicklung und der Ziele der Gesellschaft 
- ruralno planiranje za potrebe urejanja vaških naselij in bližnje okolice, po vzoru urbanističnega planiranja,

- ruralno planiranje kot celostno ali integralno planiranje družbenih in gospodarskih dejavnosti na podeželju (Prosen, 1993).

Nobeno od naštetih vrst planiranja ni v celoti odpravilo razlik med mestom in vasjo. Res je sicer, da se je na našem podeželju marsikaj spremenilo, vendar bolj po zaslugi poseljevanja primestnih naselij, kot po zaslugi konsistentne razvojne politike za podeželje.

\section{AKTIVNOSTI ZA RAZVOJ PODEŽELSKEGA PROSTORA}

Spoznanje, da velikega ali celo pretežnega dela posamezne dežele ali države ni možno enostavno prepustiti lastni usodi, je vzpodbudilo vrsto evropskih dežel k akcijam za prenovo ali razvoj podeželja in vasi.

Da razvoj podeželja in vasi ni le posamičen problem, temveč problem evropskih in svetovnih razsežnosti je potrdil sklep Sveta Evrope iz leta 1987 o razglasitvi "kampanje podeželskega prostora" v letu 1988. Namen tega sklepa je bil sprožiti akcijo spoznavanja problemov podeželja $\mathbf{v}$ vsaki deželi članici in uresničitev naslednjih ciljev:

- zagotoviti enakovredno osnovno oskrbo podeželskemu prostoru s pomočjo enakomerne razmestitve dejavnosti in $\mathrm{z}$ rabo naravnih potencialov,

- novo usmeritev kmetijstva in gozdarstva,

- nova usmeritev gospodarske politike ustrezno možnostim in življenskim razmeram podeželja,

- varovanje okolja,

- varovanje kulturne krajine, kulturne identitete in arhitekturne dediščine,

- izboljšanje življenskih razmer in reševanje socialnih problemov predvsem kmečkih žena, mladine in ostarelih.

Konkretne aktivnosti in ustrezni rezultati so se pokazali proti koncu 80 let predvsem v posameznih deželah Avstrije in Nemčije.Formalno smo k tem aktivnostim pristopili tudi mi v letu 1989, s konkretnimi koordiniranimi in spodbujevalnimi aktivnostmi pa smo pričeli šele zadnji dve leti.

\section{NAČRT ALI VIZIJA UREJANJE PODEŽELSKEGA PROSTORA}

Poučno za naše razmere je, da posebnega sistema planiranja podeželskega prostora v Evropi ne poznajo.

V Nemčiji vsebuje zvezni zakon o urejanju prostora načela za integralno prostorsko urejanje. Konkretno zvezna zakonodaja Nemčije podaja nekaj pomembnih načel in sicer o: 
- varovanju in nadaljnem razvoju podeželske strukture z zdravimi življenskimi in delovnimi razmerami kot temeljem za gospodarske, socialne in kulturne razmere,

- izboljšanju življenskih razmer s strukturnimi izboljševalnimi ukrepi na vsakem območju, ki je pod ravnijo nemškega povprečja,

- varovanju temeljev kmetijske in gozdarske rabe tal in zadostne gostote prebivalstva,

- ohranjanju, varstvu in negi krajine.

V zakonih o prostorskem planiranju zveznih dežel je v Nemčiji govora le o programih in načrtih za uresničevanje zakonskih načel, tudi planiranja podeželskega prostora. Razvoj podeželskega prostora pospešujejo z razvojnimi ali prostorskoureditvenimi programi, regionalnimi plani in posameznimi sektorskimi programi in plani (Naprudnik, Premzl, 1992). Celostni razvoj podeželja temelji na ukrepih socialne in komunalne politike, pospeševanju regionalne gospodarske moči, izboljšanju agrarne strukture, na urejanju in negi krajine .

Osrednji ukrep za razvoj podeželskega prostora je komasacija. S komasacijo ne zlagajo zgolj zemljišč, temveč z njo izboljšujejo proizvajalne in delovne razmere v kmetijstvu in gozdarstvu. Ker pa razumejo s tem dejanjem tudi uresničevanje planskih pobud za razvoj podeželskih občin, predvsem pa zboljšanje strukture podeželskega prostora, financirajo iz istega vira tudi izvedbo prometnic, oskrbo z vodo, komunalne ureditve, sanacijo posameznih javnih objektov, naprave za prosti čas in oddih, ukrepe za varstvo narave in nego krajine. Prav tako pa ni zanemariti zakonske obveznosti iz 4.člena zakona o urejanju prostora, ki obvezuje organe zveze in dežel, javne nosilce planiranja in fondacije, da uskladijo svoje načrte in ukrepe pri programih razvoja podeželskega prostora.

Na podoben način, s programi razvoja podeželja, vendar praviloma na manjših, prostorsko omejenih območjih, razvijajo podeželski prostor v Avstriji. Veliko vlogo ima v obeh državah iniciativa krajanov samih, tudi večji del izvedbe je poverjen njim samim, njihovemu lastnemu interesu. Dežela ali okraj sta pri tem programu krajanu partner.

Jasno je, da tak pristop ni planiranje. Postopki morajo biti jasni in kratki. Krajani imajo sicer podporo v obliki brezplačnega svetovanja na kraju samem, vendar v glavnem za zadeve strokovnega nasveta o gradnji in obnovi objektov, poslovanja in financiranja. Dokumentacija za realizacijo programa ni izdelana v obliki in vsebini projekta, razen za infrastrukturo.

\section{RAZVOJNI PROJEKTI PODEŽELSKEGA PROSTORA V SLOVENIJI}

Pri nas v Sloveniji se je pojavila kopica projektov na temo razvoj podeželja in prenova vasi. Značilnost teh projektov je ali pretežno analitičen pristop $\mathrm{z}$ nekaterimi smernicami nadaljnega dela in razvoja, ali pa pragmatičen pristop, največ kmetijsko sektorski in proizvodni pristop. Spoznavanje z metodologijo in prakso urejanja podeželskega prostora v nekaterih evropskih deželah, predvsem s prakso v Nemčiji in Avstriji, je prispevalo tudi k implementaciji metodologije urejanja podeželskega prostora pri nas. 
Pod skupnim imenom "projekt" so označeni vsi mogoči sektorsko obarvani pristopi (arhitektonska analiza tipologije objektov in krajine, sociološka analiza kmečkega vprašanja, agrarno proizvodni projekt,itd.). Kot poskus čistega projektnega pristopa, ki je med drugim deležen posebne pozornosti kmetijskega ministrstva oziroma njegovega Centra za celostni razvoj podeželja (CRPOV), je primer Projekt razvoja Remšnika (Občina Radlje). Vsebinska struktura projekta (brez analitičnega uvodnega dela) je naslednja:
A. Projektni cilji
B. Projekti
C. Podprojekti - fazni projekti

Podprojekti kot fazni projekti so zastavljeni $v$ obsegu, ki jih je možno izvajati časovno in vsebinsko neodvisno, so pa sestavni del projektov in ciljno smiselno zastavljeni.

Ob tej enostavni in jasni zasnovi projektnega pristopa se zastavlja vprašanje manjkajoče razvojne politike in ukrepov, ki jamčijo za izvedbo projekta ter vodenje tako obširnega projekta, sestavljenega iz preko 100 podprojektov od infrastrukture do razvoja kulture in varstva okolja. Izvedba prostorsko omejenega projekta temelji na predpostavki, da bo profesionalna organizacija koordinirala celoten projekt finančno in organizacijsko, nosilci izvedbe pa bodo posamezni interesenti sami.

Predlog posnema metodo izvajanja tovrstnih razvojnih aktivnosti pri sosedih v Deželi Štajerski vendar brez ustrezne sprejete politike in ukrepov za zagotavljanje celostnega razvoja podeželskega prostora v Sloveniji. Te v Sloveniji preprosto nimamo ali pa obstoječih parcialnih sistemskih rešitev ne moremo poimenovati s politiko in njenimi ukrepi za izvajanje.Dejstvo žal je, da si je prostor in varstvo okolja "prigrabilo" dvoje ministrstev: -podeželski prostor izven mest in večjih naselij kmetijski resor,

-mestni in naselbinski prostor večjih naselij resor urejanja prostora.

Oba resorja imata v sestavi svoje strokovne službe za urejanje prostora, eno za podeželski in eno za urbani prostor, kar vodi nadalje $\mathrm{v}$ razvoj dveh sistemov poselitve, prostorskega reda in sistemskih ukrepov za teritorialni razvoj. Tudi sistem državnega finansiranja je razcepljen na več resorjev, pri čemer vsak odveže mošnjo po lastnih merilih. V praksi pa vsak ravna po načelu, da so skupne, ne zgolj ozke interesne zadeve, naloga drugega resorja, čeprav govorijo o celostnem razvoju.Nadaljevanje tovrstnega dela in razvoja ni upravičeno zgolj iz metodoloških razlogov izvajanja razvojnih aktivnosti, temveč je družbeno škodljivo. Prostora in okolja v predvidevanju nadaljnega razvoja ni možno deliti med sektorje in ponovno uvesti zgolj sektorsko planiranje kot osnove za družbeni in prostorski razvoj države, regije in občine. Načelo integralnega planiranja je nedvomno upravičilo svoj obstoj, dasiravno imamo $v$ metodološkem pristopu $\mathrm{k}$ planiranju vrsto nerazčiščenih vprašanj. 
Filozofija, metodologija in vizija...

\section{ZAKLJUČEK}

Opisane zadrege in dileme o metodološkem pristopu celostnega razvoja podeželja so večplastne. Klasičen filozofski pristop k razrešitvi problema celostnega razvoja podeželja je verjetno potreben $\mathrm{z}$ vidika opredelitve vrednostne predstave o pomenu podeželskega prostora za narodovo in prostorsko identiteto Slovenije in podeželana v sklopu narodove, nacionalne identitete.

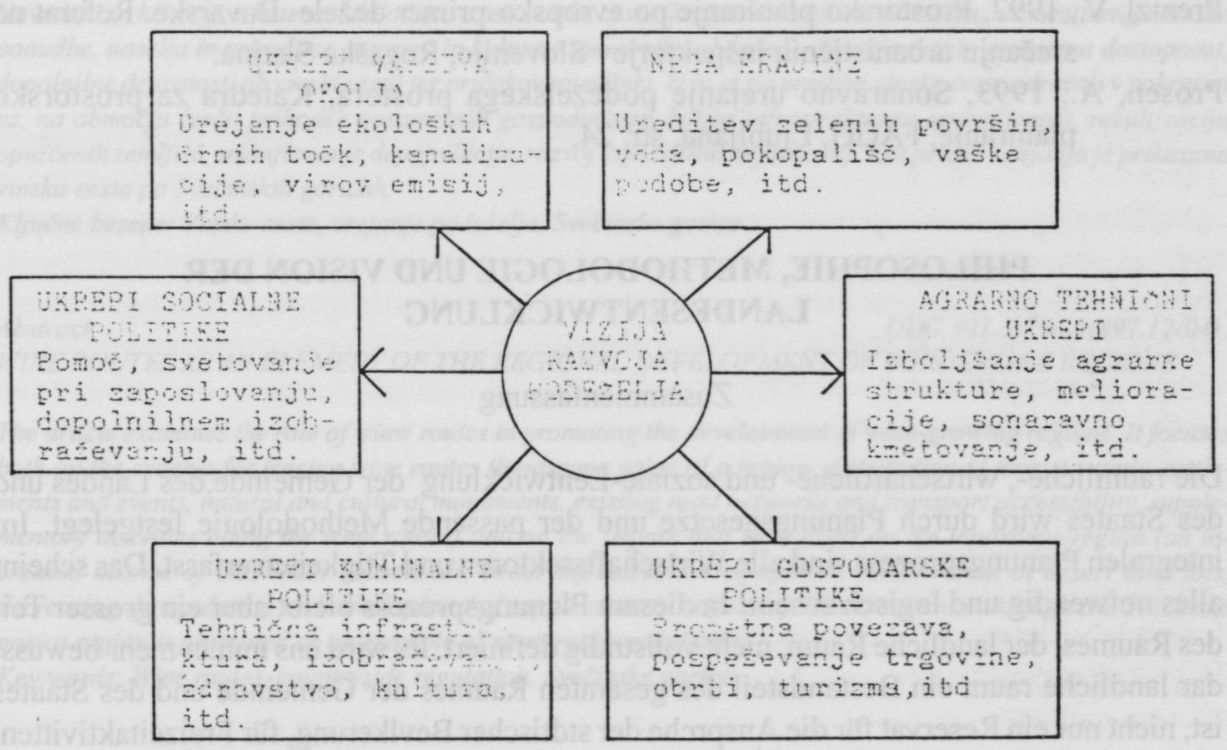

Slika 2: Predlog organiziranega pristopa k razvoju podeželja Vorschlag der Organisation der Landesentwicklung

Metodološko razvoj podeželja ni možno izločiti iz sistema bodočega celostnega razvojnega planiranja (ali kakorkoli se bo že imenovalo ?). Specifičnost podeželskega prostora tudi ni možno planirati s klasičnim instrumentarijem prostorskega in urbanističnega planiranja. Dosedanje izkušnje o uspešnosti tega postopka niso bile prepričljive . Podeželski prostor tudi ne more biti zgolj domena strategije razvoja kmetijstva v Sloveniji, pri čemer še niso razjasnjeni pogoji našega kmetijstva v pogojih EGS kamor rinemo in ki nima posluha za protežiran položaj nacionalnega kmetijstva. Pri tem je naša zemljiško lastniška struktura popolnoma neprimerna za vstop v evropske pogoje kmetijskega gospodarstva. Rešitev za pristop $\mathrm{k}$ razvoju podeželja in obnove vasi vidim zgolj $\mathrm{v}$ enovitem sistemu razvojnega planiranja države, regije in občine, $\mathrm{z}$ dolgoročno opredeljeno vizijo razvoja podeželja, ustrezno politiko in ukrepi za razvoj podeželskega prostora. 
Filozofija, metodologija in vizija...

\section{LITERATURA IN VIRI}

Buchwald, K., Engelhardt, W.-Hrsg., 1980, Handbucher Plannung, Gestaltung und Schutz der Umwelt 1: Die Umwelt des Menschen. BLV Verlagsgesellschaft, Muenchen, Wien, Zuerich. str. 137.

Naprudnik, M., Premzl, V., 1992, Urejanje prostora in varstvo okolja na Bavarskem. Aram.d.o.o. Maribor, 1992. str. 7.

Premzl, V., 1990, Oblikovanje ciljev prostorskega razvoja. IB revija za planiranje, Ljubljana, str. 8-9.

Premzl, V., 1992, Prostorsko planiranje po evropsko-primer dežele Bavarske. Referat na srečanju urbanističnih inšpektorjev Slovenije, Rogaška Slatina.

Prosen, A., 1993, Sonaravno urejanje podeželskega prostora, Katedra za prostorsko planiranje, FAGG, Ljubljana, str. 24.

\section{PHILOSOPHIE, METHODOLOGIE UND VISION DER LANDESENTWICKLUNG}

\section{Zusammenfassung}

Die raumliche-, wirtschaftliche- und soziale-Eentwicklung der Gemeinde,des Landes und des Staates wird durch Planungsgesetze und der passende Methodologie festgelegt. Im integralen Planungsprozess sind alle Wirtschaftssektoren und Ttigkeiten erfasst. Das scheint alles notwendig und logisch susein! In diesem Planungsprozess bleibt aber ein grosser Teil des Raumes, der landliche Raum, nicht vollstndig definiert. Es wird uns immer mehr bewusst dar landliche raum ein Bestandsteil des gesamten Raumes der Gemeinde und des Staates ist, nicht nur ein Reservat für die Ansprche der stdtischer Bevlkerung, für Freizeitaktivitten, oder eine Trassenfhrung verschiedenster Infrastrukturen, oder als reserviertes Bauland, u.s.w. Fast alle europische Staaten haben Aktivitten entwickelt mit der Absicht dem Indlichen Raum neue Chancen zu bieten und den Ausgleich des Lebensstandard des Staates zu erreichen.

Da ergibt sich die Frage mit welchen planerischen Mitteln kann man das erreichen. Ist die raumplnerische-, agrarplnerische Methodologie am Platz, oder sole eine zutreffende Entwicklungspolitik fr den Indlichen Raum nach entwickelt werden.

Bei der Planung des Indliches Raumes kann man eine starre, klassische Raumplanung nicht anwenden. Man solte sich lieber an die der ansessiger Bevlkerung anpassende Ziele sttzen und eine Vision der Entwicklung verfolgen, die im Rahmen des Landesentwicklungsplanes mit einer Entwicklungspolitik und mit konkreten Massnahmen ausgefhrt wird. 